\title{
Evaluating bacterial ureolysis for the low pH, high temperature and limited oxygen conditions of the deep subsurface
}

\author{
ARDA AKYEL ${ }^{1}$, ANNA MARTINSON $^{2}$, DANA SKORUPA ${ }^{3}$, \\ ADRIENNE PHILLIPS ${ }^{4}$, ROBIN GERLACH ${ }^{5 *}$ \\ Center for Biofilm Engineering, 366 Barnard Hall, Montana \\ State University, Bozeman, MT, 59717, USA \\ 1(arda.akyel@montana.edu) \\ 2(annamartinson@montana.edu) \\ 3(dana.skorupa@montana.edu) \\ 4(adrienne.phillips@montana.edu) \\ 5(*correspondence: robin_g@montana.edu)
}

\section{Aims:}

Development of biomineralization technologies has largely focused on ureolysis-induced carbonate precipitation by Sporosarcina pasteurii. However, in the deep subsurface for example, the utility of this organism is limited due to its restricted $\mathrm{pH}$, temperature and electron acceptor preferences. We set out to enrich ureolytic microbes from extreme environments and explore the ureolytic activity of microbes at low $\mathrm{pH}$ and elevated temperatures.

\section{Methods and Results:}

Anaerobic and facultative enrichments for haloalkaliphilic, ureolytic microorganisms were enriched from sediment slurries collected at Soap Lake (WA, USA). Optimal pH, temperature and salinity were determined and the dominant populations in these ureolytic enrichments were identified via a combination of high-throughput SSU rRNA gene sequencing, clone libraries and Sanger sequencing of isolates. The enrichment cultures consisted primarily of Sporosarcinaand Clostridium-like organisms. Ureolysis rates and direct cell counts in the enrichment cultures were comparable to the S. pasteurii (strain ATCC 11859) type strain. Subsequently, bacterial urease was extracted from cells and the enzyme's thermal stability and kinetics were assessed at temperatures between $20^{\circ} \mathrm{C}$ and $80^{\circ} \mathrm{C}$. The half-life of the bacterial urease decreased with increasing temperature while the rate coefficient for urea hydrolysis increased with increasing temperature. Finally, S. pasteurii cells were exposed to $\mathrm{pH}$ values between $\mathrm{pH} 3.5$ and 7 , and urease activity was quantified. Short exposure times to low $\mathrm{pH}$ values did not have a significant impact on ureolytic activity while exposure times of 1 hour and above largely inactivated the enzyme.

Conclusions and Impact of the study:

Extreme environments can harbor highly ureolytic bacteria with potential advantages for large scale applications in environments devoid of oxygen, with high temperature, low $\mathrm{pH}$ values and other stressors. 